JOSÉ FAUSTO • Desarrollo de micrometraje animado, una propuesta desde el diseño centrado en el usuario con enfoque social.

\title{
Desarrollo de micrometraje animado, una propuesta desde el diseño centrado en el usuario con enfoque social ${ }^{1}$
}

Development of animated micro-film, a proposal from the user-centered design with a social focus

\author{
José Mota Mata ${ }^{2}$ \\ UniVERSIDAD AutónOMA CiUdAD DE JUAREZ. MÉXICO.
}

Resumen. En este escrito se describe el proceso de elaboración de un micrometraje animado realizado con el objetivo de fomentar el sentido de pertenencia y arraigo a una comunidad. Como caso de estudio, el proyecto está enfocado hacia usuarios del Fraccionamiento Urbivilla del Cedro, un conjunto habitacional localizado en una de las periferias suroriente en Ciudad Juárez, México. La propuesta en formato de micronarrativa surge a partir de las adecuaciones, generadas por la pandemia del coronavirus SARS-COV2, a un proyecto de diseño social denominado ColorEs Finca Bonita, el cual está enfocado en resignificar paisajes urbanos a través de la gráfica urbana. La metodología para la construcción del micrometraje se basa en un estudio cualitativo de diseño centrado en el usuario, con herramientas de corte etnográfico, donde el investigador asumió un rol de observador participante, así como una perspectiva que considera las actividades en el espacio público urbano. Esto permitió constatar una diversidad de identidades y una serie de prácticas socio-económicas, donde la principal de ellas es la instalación de un mercado informal. Las prácticas responden a la apropiación de un diseño urbano que no favorece a sus habitantes, la mayoría de ellos trabajadores de la industria manufacturera, en una ciudad caracterizada por la fragmentación urbana y expansión hacia las periferias. En suma, la producción del micrometraje se centra en visualizar representaciones espaciales e identitarias para favorecer la construcción de imaginarios y sentido de arraigo a un espacio público.

Palabras clave. Diseño Social; Identidad; Resignificación; Espacio Público; Micrometraje.

Abstract. In this paper, the process in the development of an animated micro-film made with the aim of fostering a sense of belonging and roots to a community is described. As case of study, this project is focused on users of the Fraccionamiento Urbivilla del Cedro, a housing complex located in one of the southeastern peripheries of Ciudad Juárez, México. The proposal in micronarrative format arises from the adjustments, generated by the SARS-COV2 pandemic, to a social design project called ColorEs Finca Bonita, which is focused on resignifying urban landscapes through urban graphics. The methodology for the construction of the micro-film is based on a qualitative study of user-centered design, with ethnographic tools, where the researcher assumed the role of participant observer, as well as a perspective that considers the activities in the urban public space. This made it possible to verify a diversity of identities and a series of socio-economic practices, where the main one is the stablishment of an informal market. Practices that respond to the appropriation of an urban design that does not favor its inhabitants, most of them workers in the manufacturing industry, in a city characterized by urban fragmentation and expansion towards the

\footnotetext{
${ }^{1}$ La investigación realizada es financiada mediante una Beca doctoral por parte de CONACYT (Consejo Nacional de Ciencia y Tecnología) para cursar el Doctorado en Diseño en la Universidad Autónoma de Ciudad Juárez. México

${ }^{2}$ Maestria en Estudio y Procesos Creativos en Artes y Diseño. Estudiante doctorado en Diseño. Universidad Autónoma de Ciudad de Juarez. México. Mail: cienciacbk@ hotmail.com.
} 
peripheries. In short, the production of the micro-film focuses on visualizing spatial and identity representations to favor the construction of imaginaries and a sense of roots in a public space.

Keywords. Social Design; Identity; Resignification; Public Space; Microfilm.

\section{Introducción}

La manera de entender el espacio público y de vivir en comunidad se alteró a partir de la pandemia ocasionada por coronavirus SARS-CoV-2. En Ciudad Juárez, México, al igual que en otras ciudades del mundo, la desigualdad social muestra que las personas asimilan de distintas formas la situación. Mientras que algunos sectores de la sociedad pueden mantener un confinamiento, existen otros grupos de la sociedad para los que fue imposible no salir de sus hogares a buscar el sustento diario. En este sentido, los procesos de identidad y sentido de arraigo entran en crisis, al igual que la economía, lo social y la salud. Además, desde el inicio de la cuarentena recomendada por las autoridades gubernamentales, distintos proyectos se vieron en la necesidad de adaptar estrategias para continuar con sus propósitos.

En este escrito, se describe el proceso para una animación, en formato de micrometraje, planteada con el propósito de continuar con los objetivos del proyecto ColorEs Finca Bonita, el cual busca resignificar un paisaje urbano, cuyas actividades se vieron afectadas por la pandemia. Como caso de estudio, el proyecto de diseño social se realiza en el conjunto habitacional de vivienda tipo social Fraccionamiento Urbivilla del Cedro, también conocido como Finca Bonita, ubicado en la periferia suroriente de Ciudad Juárez, México. Este micrometraje en animación se construye en consideración a las nociones de paisaje urbano, identidad y comunidad, con un enfoque espacial. En otros términos, se desarrolla en el plano de los procesos identitarios en relación a la construcción de imaginarios colectivos de determinados espacios públicos urbanos.

Esta investigación se fundamenta en los resultados preliminares obtenidos en la tesis doctoral Resignificación del entorno a través de la gráfica urbana y ejercicios con la comunidad. Caso de estudio Fraccionamiento Urbivilla del Cedro en Ciudad Juárez, del autor de este artículo, la cual tiene el objetivo principal de cambiar los significados atribuidos a un espacio público que no favorece el sentido de arraigo, a través del proyecto ColorEs Finca Bonita. Con ello, se buscó la participación de los habitantes para resignificar su propio entorno a través de actividades relacionadas a la gráfica urbana, tales como la pinta de murales en colaboración y la impartición de talleres de dibujo en espacios públicos del fraccionamiento. La implementación de las distintas acciones de este proyecto se hizo acorde a la revisión de propuestas de metodologías participativas realizadas por Paisaje Transversal (2019) y métodos de acercamiento al usuario descritos por Kumar (2013). Así mismo, es importante señalar que este proyecto se realiza de manera autogestionada y con recursos limitados, por lo cual la participación comunitaria es comprendida como una herramienta más que un objetivo a lograr.

Debido a la pandemia y las restricciones para realizar actividades en el espacio público, el proyecto ColorEs Finca Bonita quedó suspendido. De tal manera, se decidió trabajar en un plano virtual y así continuar con la resignificación del paisaje urbano por medio de una propuesta audiovisual. Es así que se pretende generar un cambio en el imaginario colectivo asociado al Fraccionamiento Urbivilla del Cedro, a través de la representación de algunos de los espacios públicos con mayor reconocimiento por parte de sus usuarios y la construcción de personajes inspirados en los mismos habitantes. En este sentido, se busca responder a la pregunta: ¿cómo fomentar significaciones al imaginario colectivo de un espacio público y favorecer el sentido de arraigo en sus usuarios a través de una propuesta de micrometraje animado? 
JOSÉ FAUSTO • Desarrollo de micrometraje animado, una propuesta desde el diseño centrado en el usuario con enfoque social.

\section{Marco teórico}

El desarrollo de este escrito parte del supuesto de que un micrometraje animado, cuyos entornos son representaciones de espacios públicos reconocibles por los habitantes de un determinado conjunto habitacional y donde los personajes están basados en las identidades de los mismos usuarios, puede contribuir a fomentar el sentido de pertenencia si se consideran las experiencias del usuario, el imaginario colectivo y las prácticas espaciales. La importancia de estructurar un producto audiovisual, desde un enfoque de diseño social basado en las nociones de comunidad e identidad, radica en las posibilidades de favorecer procesos de generación de memorias colectivas y sentido de pertenencia.

A través de proyectos denominados como diseño social, se han generado distintas propuestas para solucionar problemáticas vinculadas a la falta de inclusión y la desigualdad social. Para esclarecer enfoques terminológicos y distinguir puntos en común, en relación a la diversidad de proyectos de diseño vinculados a lo social, Ledesma realizó un ejercicio cartográfico basado en la implementación y objetivos propuestos en más de cien grupos de diseño social. Esto le permitió a la autora generar una clasificación con base a los puntos nodales resultado de la cartografía empleada. De acuerdo a la taxonomía de Ledesma, nuestra propuesta de micrometraje se ubica como un proyecto de diseño social, porque con la implementación de herramientas relacionadas a la gráfica y el diseño, se tiene el objetivo de favorecer en la construcción de identidades en una comunidad (72).

La conformación de las identidades se lleva a cabo en procesos durante los cuales se asimilan las particularidades ligadas a las culturas. La memoria colectiva otorga a los miembros de una determinada comunidad la posibilidad de identificarse respecto a otros grupos sociales. Lo que permite a un grupo de la sociedad ser identificado, para sí mismo y hacia los otros, tiene que ver con la permanencia en el tiempo de determinadas características y esquemas aprehendidos socioculturalmente que quedan registrados a modo de un imaginario compartido. Al respecto, Mendoza (2009) señala que la identidad es algo que perdura sin aparente cambio durante algún tiempo, pero que en tiempos de crisis, esta puede verse alterada (59). En este sentido, la memoria actúa como un mecanismo que modera aspectos de la cultura y la identidad en comunidades.

Por otra parte, el uso generalizado del Internet a finales de los años 90 y de aplicaciones en los dispositivos móviles, como las redes sociales a finales de los años 2000, alteraron los procesos en la construcción de identidades. Entre los diversos cambios ocasionados por este fenómeno, se encuentra el sentido de arraigo hacia los territorios y a determinados espacios públicos. Asimismo, los usuarios tienen la posibilidad de mostrar, en el espacio cibernético, una alteridad moldeable a sus requerimientos que no necesariamente corresponde a la identidad que exhiben al estar en los espacios públicos urbanos. En otras palabras, se agregan capas de sentido y significado en un proceso que tiende a la desvinculación del espacio físico, tal como apunta Casas (2002) "Mientras que anteriormente las identidades eran definidas en función del lugar de nacimiento, de los padres, de la cultura, de la religión, o de la raza, en las nuevas redes tecnológicas no existen dichos condicionamientos" (39).

En este sentido, el espacio público urbano, como soporte de las identidades, se desliga en la búsqueda de sentido de pertenencia. Esto sucede en ciudades como Juárez, México, donde el diseño urbano ha sido planificado de acuerdo a esquemas mercantiles en un área de semidesierto, 
donde además, se ha privilegiado la construcción de los parques industriales ${ }^{3}$, mientras existe una precarización de servicios en otras zonas de la ciudad. Los usuarios han generado dinámicas para dotar de nuevos significados al espacio público urbano, ya que, como indica Vicherat (2007), este continúa como soporte de reconocimiento. Es así que la identidad, entendida como un constructo, se produce por la socialización urbana que permite reconocernos a nosotros mismos en relación a los otros (59).

En consecuencia, la constante reconfiguración del espacio público urbano, en conjunción con los procesos identitarios, establece un continuo flujo de significados y simbolismos. La resignificación de los lugares implica un proceso en el cual se agregan, conjugan, eliminan, alteran o transforman sus significados atribuidos. Por ejemplo, en el Fraccionamiento Urbivilla del Cedro se generan diversas prácticas que disocian el sentido original de algún espacio público, como la instalación de puestos de ventas de artículos, nuevos o usados, instalados en las banquetas o en terrenos baldíos. De esta manera, los usuarios otorgan otro significado a espacios públicos urbanos, los cuales no podrían ser considerados como lugares sin la apropiación realizada por los mismos usuarios.

De este modo, es importante tomar en cuenta las reconsideraciones a la noción de espacio público urbano a partir de las reflexiones realizadas por Lefebvre y Soja. Estas perspectivas posibilitan la comprensión de cómo es la construcción de paisajes urbanos y cómo contribuyen al desarrollo de imaginarios y, por lo tanto, funcionan para generar representaciones de cómo es el espacio vivido y la percepción atribuida a los principales nodos de una unidad habitacional específica. Para Lefebvre, la producción del espacio público urbano está relacionada al neocapital y su entendimiento implica reflexionar en torno a cuestiones complejas como la relación entre las fuerzas de trabajo y el mercado (92). Este autor plantea que no es posible una verdadera comprensión del espacio social si solo se le estudia a partir de las representaciones, o a través de perspectivas parciales. En este sentido, señala al cuerpo como el inicio para entender el espacio y define que existe una dialéctica a partir de la triada: lo percibido, lo concebido y lo vivido (99).

Asimismo, Lefebvre refiere a las lógicas de mercado y relaciones de poder en la configuración de las ciudades. De igual manera, apunta a la utilización de figuras retóricas en lo que define como una doble lógica espacial con el uso de la metáfora y la metonimia (153). Por ejemplo, en relación al espacio y el desarrollo urbano, en las ciudades se llevan a cabo los planes para la expansión de las mismas o bien la construcción de complejos habitacionales, parques industriales, zonas comerciales, entre otros planes inmobiliarios. Sin embargo, estas prácticas comerciales esquematizan el espacio y reducen las complejidades que llevan a su configuración. En otras palabras, el usuario no es considerado, sino que se reducen a una metáfora o una metonimia los factores que determinan la producción del espacio en una capitalización tendiente a la desaparición de las áreas naturales.

Al continuar con las reflexiones de Lefebvre, conceptualiza una trialéctica del espacio. Se trata de tres perspectivas que buscan ir más allá de los tradicionales entendimientos del espacio como algo físico y subjetivo. Soja define el primer espacio en relación con las prácticas espaciales. El segundo espacio involucra a las representaciones del espacio, tales como los mapas mentales y las cartografías de los urbanistas. El tercer espacio se entiende como la simultaneidad de los dos primeros espacios y se concibe como el espacio vivido (40). Para Soja, el espacio vivido representa lo simultáneo de estar en el espacio público. Se puede comprender a modo de un traslape de capas donde se encuentran: la percepción a través de los sentidos de los aspectos materiales y simbólicos

\footnotetext{
${ }^{3}$ Los parques industriales son áreas de la ciudad destinadas a la construcción y operación de naves industriales o bien fábricas donde se ensamblan distintas piezas desde electrodomésticos a partes de automóviles.
} 
JOSÉ FAUSTO • Desarrollo de micrometraje animado, una propuesta desde el diseño centrado en el usuario con enfoque social.

del espacio, los mapas mentales, las representaciones que los usuarios generan de los espacios donde transitan, así como, las experiencias de vida de los usuarios y sus esquemas que asocian significaciones a los espacios y conforme son vividos se van resignificando (40).

Tanto en el pensamiento de Lefebvre como en el de Soja se considera que el espacio público urbano debe ser comprendido de una manera compleja. Para estos autores, las representaciones espaciales únicamente visualizan de manera parcial algunas de las prácticas espaciales. Aunque estos planteamientos amplían el entendimiento de la concepción espacial y ayudan a visualizar cómo es que a través de las perspectivas mercantiles se aminoran los complejos esquemas donde actúan estructuras de poder, hay que considerar que la esquematización del espacio en nuestra propuesta de micrometraje no obedece, ni es generada desde una perspectiva de privilegio en relación a los habitantes. Se trata, más bien, de utilizar las representaciones espaciales por medio de distintas visualizaciones y emplearlas a modo de herramientas para comprender de mejor manera cómo se vive el espacio público en la unidad habitacional objeto de estudio.

De esta manera, se comprende que al estar en un espacio público, este determina patrones de comportamiento los cuales se conjugan con esquemas previos de cada usuario. Existen distintos tipos de espacio públicos, privados o semi públicos, que determinan diversos patrones de proceder. Para ilustrar esto, hay lugares de paso, los cuales conectan entre un punto y otro. En este sentido, la calle o las sendas por las que un usuario sale de su hogar para ir a otro punto, ya sea la tienda, el punto de abordaje de transporte público, el trabajo, o cualquier otro lugar, representan lo que Delgado refiere como espacios trasversales. Estos pueden comprenderse como puentes que interfieren en las maneras de actuar por parte de quienes transitan por ellos (35). De este modo, el usuario que recorre una calle se encuentra en una especie de alteridad. En otros términos, se le puede referir como un transeúnte. Para efectos de nuestra investigación, consideramos a este tipo de usuario como clave. Es decir, la figura del transeúnte nos permite hacer una distinción y no delimitar la noción de identidad a un estereotipo, sino más bien, comprender que existen diversas identidades y que un mismo usuario puede portar elementos que lo identifiquen a una o varias colectividades, pero que la característica que determina al transeúnte es la de estar en una especie de pasaje que lo conecta desde un punto de origen a otro punto de destino.

Para comprender cómo se desarrollan los procesos identitarios en los habitantes, es preciso comenzar por abordarlo desde su contexto general. La condición de frontera de Ciudad Juárez con Estados Unidos, en conjunto con fenómenos como la migración, desarrollan elementos en la configuración de las identidades. La frontera de las ciudades de Juárez, México y El Paso, Texas en Estados Unidos manifiesta ya algunas particularidades. Existe una desigualdad en el desarrollo económico entre ambas ciudades. Asimismo, en el imaginario colectivo, Ciudad Juárez fue el lugar de diversión y de vida nocturna durante algunas décadas del siglo pasado, mientras que El Paso representa mejores oportunidades de trabajar con un sueldo superior. De igual forma, la disparidad se muestra con fenómenos como el incremento de la violencia ocurrida a partir del año 2007 que derivó en el nombramiento como una de las ciudades más peligrosas del mundo a Ciudad Juárez. En contraste, El Paso, Texas fue referida como una de las ciudades más estables de Estados Unidos. Por otra parte, la industria de la transformación, o de la maquiladora ${ }^{4}$, es la principal actividad económica y de desarrollo para los habitantes. Además, desde la década de los años 70 del siglo

\footnotetext{
${ }^{4}$ La industria de la transformación, o de la maquila como es conocida en la frontera, es una de las principales fuentes de trabajo para los ciudadanos fronterizos. Sin embargo, las condiciones laborales representan una desventaja para los trabajadores, quienes tienen salarios mínimos y en algunas fábricas las jornadas de trabajo son de más de 8 horas diarias debido al tiempo extra.
} 
pasado, esta actividad ha desempeñado un rol estructurante en la conformación del diseño urbano de la ciudad. Esta industria transformó la forma de vivir en esta frontera. Actualmente, se puede distinguir la expansión de la ciudad hacia las periferias, principalmente al suroriente. Se trata de una mancha urbana caracterizada por la ubicación de extensos parques industriales y zonas habitacionales, en su mayoría de viviendas de tipo social, además de algunos centros comerciales $\mathrm{y}$, durante los últimos años, por la constante construcción de plazas comerciales y naves industriales. El desarrollo urbano de la ciudad se muestra fragmentado. Entre amplias zonas de terreno de desierto y la lejanía de centros de salud, educación y esparcimiento, aunado a un deficiente sistema de transporte público, para los habitantes de las periferias de la ciudad, la calidad de la habitabilidad se ve precarizada. Estas son algunas características a considerar en la construcción de imaginarios e identidades respecto a las distintas zonas de la ciudad, aspectos que ayudan a entender cómo es vivir la ciudad.

En cuanto a la propuesta para adaptar la búsqueda de resignificación de paisajes urbanos, en nuestro caso de estudio, se plantea el formato del micrometraje, entendido como la proyección audiovisual de un relato breve o micronarrativa cuya duración no excede los 3 minutos. Esta idea surge también por las posibilidades que plantean el software libre Blender, en la producción autogestionada de productos audiovisuales a bajo costo, donde la implicación es saber utilizar las herramientas de animación. El micrometraje, como formato de comunicación de narrativas, surge de la preponderancia en la inmediatez por brindar y obtener información requeridas en la sociedad actual, tal como señala Escobedo “... esa inmediatez sólo responde a la narración fragmentada en paquetes" (27). Quizá esta sea la causa de la propagación de videos cortos en Internet y la efervescencia de productos audiovisuales con una duración de segundos. Sin embargo, queda también la reflexión en torno a la abundancia de imágenes y de información sin un contenido propositivo, es decir que para los usuarios de redes sociales existe un bombardeo de videos e imágenes que no aportan al pensamiento o a la reflexión.

Por otra parte, la brevedad en el micrometraje se considera en proporción al largometraje, sin embargo, no se trata únicamente de una reducción en la duración del producto. En relación a la micronarrativa, Malaver (124), plantea que más allá de la miniaturización, lo que se pretende es lograr una reconfiguración a partir de la limitación en recursos narrativos y de tiempo. De igual manera, refiere que la comprensión de lo que se pretende narrar depende de lo que el lector conozca previamente, es decir, que son necesarios recursos como la sinécdoque o la metáfora para completar los vacíos que en una micronarrativa se establecen. En este sentido, se requiere de un espectador con conocimientos previos, respecto a los significados que se le presentan, para que la idea proyectada sea plenamente comprendida.

\section{Metodología}

Esta investigación fue de corte cualitativo, se integraron herramientas de investigación propias de la etnografía, tales como la observación participante, el registro fotográfico y en video de lugares de mayor socialización en la unidad habitacional y entrevistas semi estructuradas a habitantes del fraccionamiento, quienes, por sus actividades económicas, conocen a profundidad las dinámicas sociales y económicas desarrolladas en el lugar. El periodo de tiempo de observación participante abarcó los meses de junio de 2019 a enero de 2020. De esta manera, el investigador adoptó un rol de etnógrafo urbano, al participar activamente en la calle con intervenciones de gráfica urbana, acciones de muralismo colaborativo y, al mismo tiempo, observar las interacciones que ocurrían en ese espacio. Estos ejercicios representan una aproximación a lo que Delgado (12) define como antropología urbana, al tener en cuenta que la comprensión de lo urbano implica una red de 
JOSÉ FAUSTO • Desarrollo de micrometraje animado, una propuesta desde el diseño centrado en el usuario con enfoque social.

relaciones que establecen los usuarios y que tienen soporte en los espacios públicos. De este modo, el investigador se integra como un agente más que realiza actividades en la calle en búsqueda de elementos de información para generar un acercamiento a las prácticas realizadas en las principales sendas de dinamismo social en el caso de estudio.

Asimismo, de acuerdo a una perspectiva espacial, se hicieron ejercicios cartográficos para registrar los principales nodos de interacciones sociales, económicas y culturales del Fraccionamiento Urbivilla del Cedro. Desde este punto de vista, otro de los instrumentos para recolectar información consistió en realizar diversos recorridos por el fraccionamiento, para de esta forma, estar consciente de aspectos que quedan reducidos u omitidos en un ejercicio cartográfico; se trata pues, de vivir el espacio público. Por ejemplo, hay sensaciones de desagrado al encontrar animales muertos, tales como perros y gatos, que generan una contaminación visual y olfativa. Asimismo, percatarse de la acumulación de desechos en terrenos baldíos o casas abandonadas producen distintas sensaciones que van desde el desagrado a la inseguridad. De igual manera, resultan relevantes para el estudio, tomar en cuenta la generación de distintas percepciones al estar en calles diferentes y observar cómo, aquellas que se encuentran en la periferia, no solo del fraccionamiento sino de la ciudad, al lado de un extenso terreno de semidesierto, pueden llegar a provocar angustia y miedo para aquel usuario que se encuentra entre casas habitación abandonadas y una amplia extensión de terreno natural del desierto.

Es así que los resultados de la investigación etnográfica consideraron recorridos en caminatas, registrados en bitácoras. Como se muestra en la figura 1, se apuntaron aspectos relevantes tales como el abandono de decenas de casas, la acumulación de basura en los terrenos baldíos, registro de representaciones gráficas en memoria de personas fallecidas, las cuales fueron encontradas en diferentes puntos del fraccionamiento, así como la observación de espacios donde los usuarios realizan las principales actividades económicas, recreativas y sociales. Además, se encontró que, a pesar de que ciertos espacios no fueron diseñados con el propósito de generar dinámicas sociales, existe una apropiación del espacio público por parte de los habitantes. En este sentido, la cuestión espacial muestra que las prácticas sociales y económicas no están determinadas únicamente por el diseño de las infraestructuras urbanas, sino que los propios usuarios viven su espacio de acuerdo a sus esquemas y necesidades sociales, culturales y económicas. 
Registro fotográfico de recorrido realizado los días viernes 7 y domingo 9 de junio de 2019 en horario de 6:00 pm a 7:00 pm y de 8:00 am a 9:00 am respectivamente. Calles recorridas Monte del Cantal y Monte Blanco.
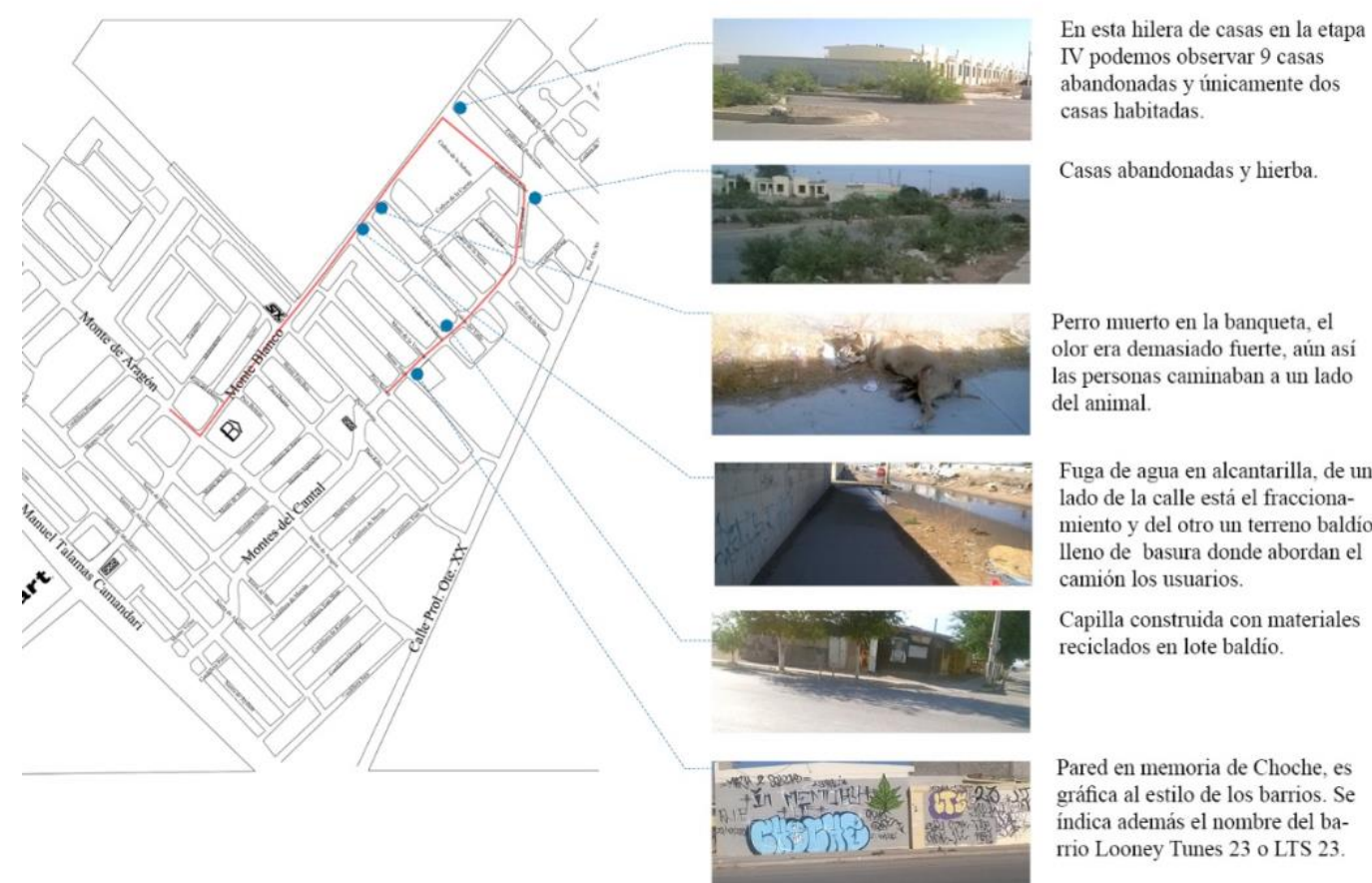

Figura 1. Registro en bitácora de recorrido por calles del Fraccionamiento Urbivilla del Cedro. 2019. Fuente: elaboración propia.

En cuanto al enfoque centrado en el usuario, a la par de la observación participante, se realizaron ejercicios de acuerdo a algunos de los métodos propuestos por Kumar para encontrar innovaciones en productos de diseño. Se trata de una perspectiva donde a través de dinámicas y registro de actividades realizadas, con y por los usuarios, se consideran aquellos aspectos que posibilitan la mejora, o integración de algunas características, para la elaboración de algún producto (218). En nuestro caso, primero se llevaron a cabo ejercicios que permitieron detectar usuarios claves y anotarlos en un cuadro de posibles participantes o informantes. Posteriormente, se efectuaron entrevistas semiestructuradas, así como también se obtuvo información importante con pláticas informales con usuarios que detallaron aspectos de sus actividades económicas y parte del desarrollo histórico que les tocó vivir en la unidad habitacional.

Resultado de los acercamientos preliminares, se encontró que la principal actividad social y económica en el Fraccionamiento Urbivilla del Cedro es la instalación de un mercado irregular, durante los días jueves a domingo en un horario que habitualmente es de 3:00 pm a 9:00 pm. Se trata de varios puestos, instalados de manera informal, donde se ofertan distintos productos y servicios. El registro y la revisión de las principales actividades llevadas a cabo en este mercado encaminó el diseño de un producto editorial para obtener información adicional y establecer colaboración con algunos de los usuarios. De acuerdo a los métodos planteados por Kumar se trata de hacer uso de un artefacto cultural, ya que surge de la observación semi estructurada de la interacción de los usuarios con productos cotidianos (183). En específico, la herramienta que posibilitó idear un producto editorial, el cual se definió realizar en formato de fanzine para colorear, consistió en conjugar varias características encontradas en el mercado. La primera observación evidenciada es que las personas regularmente acuden en grupo, en familia o en parejas y frecuentemente con niños. La segunda observación fue el apunte de los productos disponibles a la 
JOSÉ FAUSTO • Desarrollo de micrometraje animado, una propuesta desde el diseño centrado en el usuario con enfoque social.

venta en el mercado, entre los cuales destacó la oferta de cuadernos para colorear diseñados con personajes de películas o series animadas dirigidas a un público infantil. La disponibilidad de estos cuadernos en varios de los puestos y el hecho de que niños acudan al mercado acompañados de sus familiares indica que se trata de un producto que es consumido habitualmente y remite al tiempo de esparcimiento de las personas.

De esta manera, se ideó la elaboración de un fanzine para colorear pero con una temática dedicada a los lugares en la unidad habitacional. Este producto editorial se compone de ilustraciones en blanco y negro de lugares del fraccionamiento y fue titulado "Cuaderno para colorear tu barrio". Como dinámica, se puso a disposición de los usuarios en puestos del mercado y se solicitó a los mismos que enviaran fotografías de cómo lo habían intervenido. La importancia de este fanzine radica en la posibilidad, para los habitantes interesados, de contar con un producto que trata específicamente del lugar donde viven. Con las intervenciones de usuarios a algunos de los ejemplares, se estableció que reconocieron las imágenes representadas y asociaron mediante el uso de color los lugares de abandono, de diversión y de mayor tránsito, tal como se muestra en la figura 2. Por otra parte, con este fanzine se buscó mostrar actividades cotidianas, tales como abordar el transporte público o caminar por las principales calles, imágenes acompañadas con frases abiertas o preguntas que pretenden llevar al usuario a reflexionar en relación a su entorno.

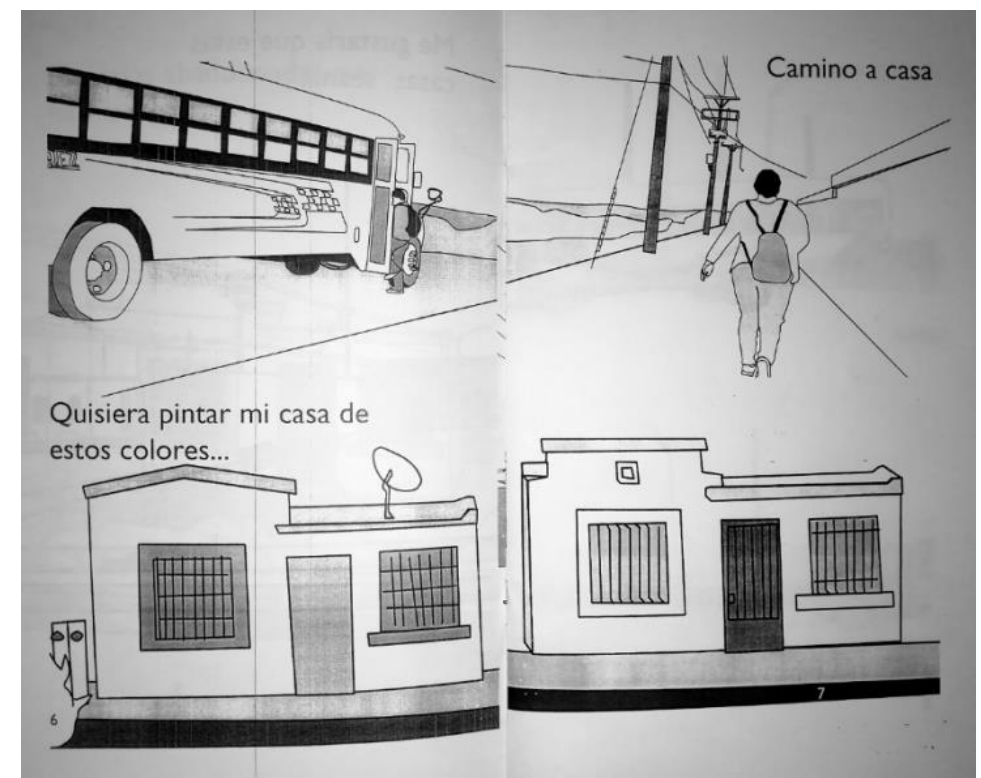

Figura 2. Páginas interiores del fanzine para colorear. 2020. Fuente: elaboración propia.

Es así que este ejercicio de acercamiento al usuario permitió generar información y desarrollar propuestas dirigidas a un grupo específico. Con el fanzine para colorear, se estableció que existe un reconocimiento a los espacios públicos de mayor tránsito; mientras que algunos lugares como las casas abandonadas o calles secundarias no fueron reconocidas por algunos de los usuarios del cuaderno. Para efectos de nuestra propuesta de micrometraje, los resultados de este ejercicio pueden funcionar para establecer ideas basadas en las intervenciones, así como analizar la manera de representar los espacios públicos que suponen abandono, o por el contrario, los que se asocian a la diversión y esparcimiento.

En suma, la recolección de datos basada en herramientas utilizadas en la etnografía, en conjunto con ejercicios que se centran en las actividades de los usuarios del fraccionamiento, es 
decir, una perspectiva espacial, permiten conocer información que puede ser traducida en propuestas que funcionen para mejorar la imagen del conjunto habitacional, tanto para sus habitantes como para quienes hacen uso del lugar. En otros términos, se fomenta un imaginario con atributos de positividad asociado al lugar. En este sentido, centrar la atención en los usuarios con instrumentos en los que se mezclan la cartografía y la gráfica, como el fanzine para colorear, ayuda a la comprensión de cómo es la percepción hacia determinados espacios.

Respecto al desarrollo del micrometraje animado, la construcción en el diseño de los personajes se aborda a partir de la observación participante. Esto es el registro gráfico en actividades realizadas en los principales puntos de interacción del fraccionamiento, que se ubican en la calle principal donde confluyen gran cantidad de transeúntes. El propósito es establecer un diseño de personajes alejado de los enfoques comerciales para mostrar un aspecto más apegado a las identidades y corporeidades de los habitantes del caso de estudio. Si bien se propone una animación al estilo de la caricatura, con las representaciones de los cuerpos no se busca validar los estereotipos impuestos desde la publicidad, es decir la idealización y sexualización del cuerpo.

Después de la fase de recolección y análisis de información, el proceso de producción para el micrometraje consistió en métodos ya establecidos o estandarizados en la producción de animaciones, donde se contempla la ideación con un guion inicial, desarrollo de un guion gráfico o storyboard, modelado de personajes y escenario, seguido de la producción y la posproducción del producto audiovisual. Sin embargo, al integrar un enfoque espacial y los resultados obtenidos con la observación participativa, se busca que los personajes y escenarios representados permitan una identificación con los usuarios y se posibilite la obtención de los propósitos establecidos de atribuir significaciones al espacio público y generar un sentido de arraigo. En la figura 3 se muestra el diagrama implementado para la construcción del microrrelato animado.

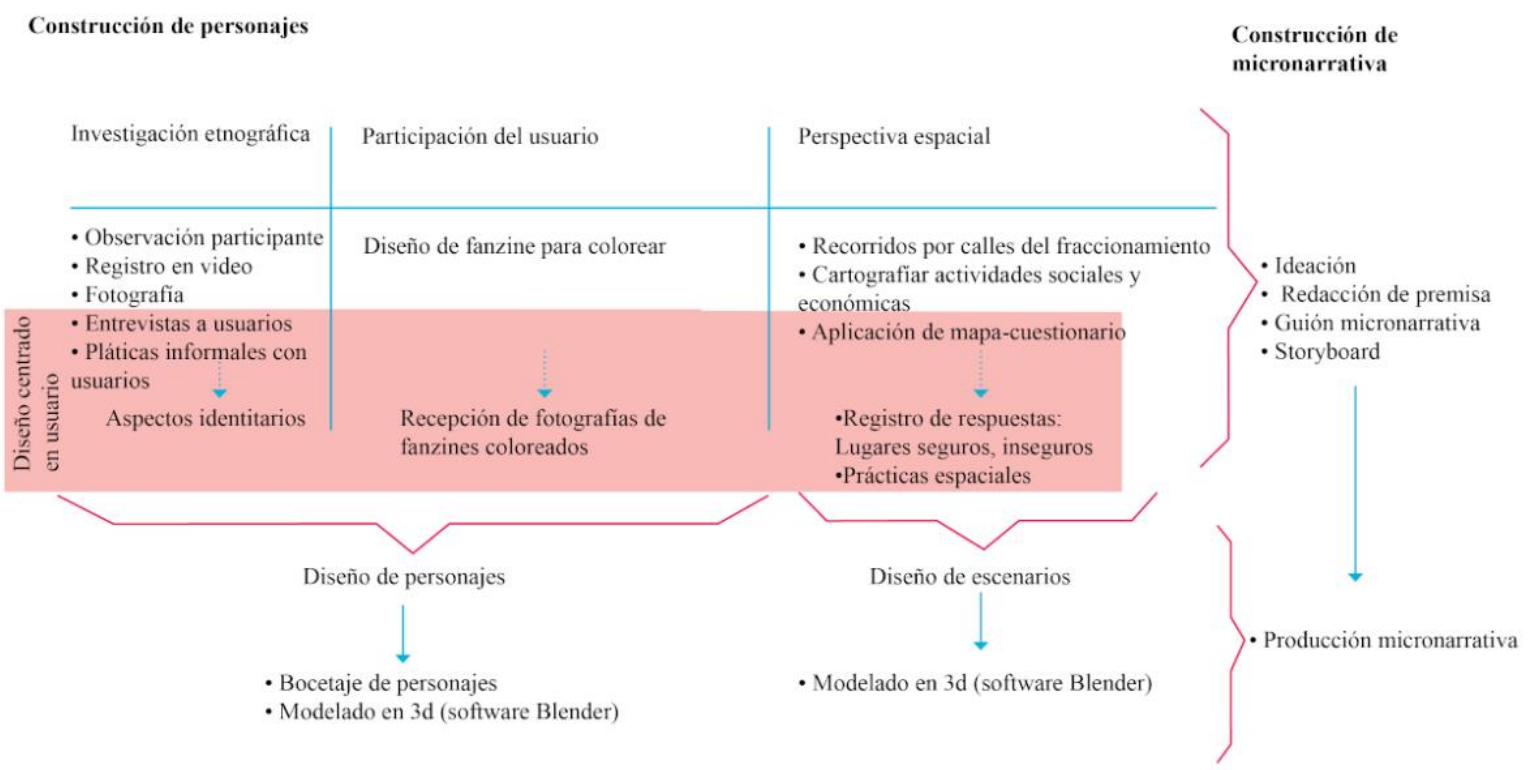

Figura 3. Diagrama de proceso de trabajo en micrometraje animado. 2020. Fuente: elaboración propia.

De igual manera, es preciso considerar lo que planteó Egri (60) respecto a la construcción y desarrollo de una historia. Si bien este autor establece una serie de puntos que hay que considerar para la construcción de personajes y guiones para teatro, en un microrrelato es necesario también estructurar una base sólida para contar una historia con los elementos suficientes y así el usuario comprenda la idea general. En este sentido, Egri (60) señala como elemento estructural en la 
JOSÉ FAUSTO • Desarrollo de micrometraje animado, una propuesta desde el diseño centrado en el usuario con enfoque social.

generación de narrativas el establecimiento de una premisa, la cual funciona a modo de tesis que es preciso comprobar a través de una estructura narrativa en conjunto con los personajes de la historia. De esta forma, el autor propone la construcción de los personajes desde una tridimencionalidad donde se procura establecer la fisiología, sociología y psicología del personaje, puntos que no se relatan al espectador necesariamente, pero que el autor conoce y debe tomar en cuenta para desarrollar las acciones que realizará el personaje. En un micrometraje, estos puntos no están demás, ya que permiten generar una coherencia en torno a las acciones y reacciones de los personajes, aún en un periodo de tiempo contado en segundos.

A partir de estas consideraciones, resultado de la investigación, en nuestra propuesta de micrometraje se establece la siguiente premisa: el amor de la familia puede cambiar al irresponsable. En este sentido, el microrelato se estructura en base a situaciones cotidianas. La sinopsis es la siguiente: el personaje principal, un joven empleado en una empresa maquiladora, está casado y tiene una hija. Al llegar al fraccionamiento, después de trabajar, se baja del transporte público y camina por la calle principal rumbo a su casa. De manera irresponsable, se quita su cubrebocas y lo tira en el suelo. Una fuerte ráfaga de viento, provocada por la velocidad con la que pasa un camión de transporte público, hace que el cubrebocas se levante y posteriormente es elevado por el aire. Este le cae en la cara al personaje principal. El personaje principal se desconcierta, pero al observar la marca de un corazón, recuerda que fue su hija quien le enfatizó se pusiera el cubrebocas justo al salir de su casa rumbo al trabajo. El personaje principal, en este punto de la trama, entra en conflicto consigo mismo. Entonces toma consciencia y decide guardar el cubrebocas para después tirarlo en la basura. En la figura 4 se muestra el borrador del storyboard. La idea principal es establecer los planos y los tiempos en los que la micronarrativa se desarrolla. 

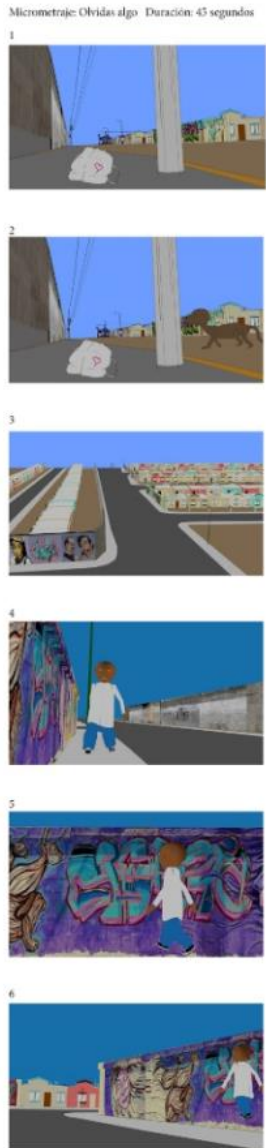
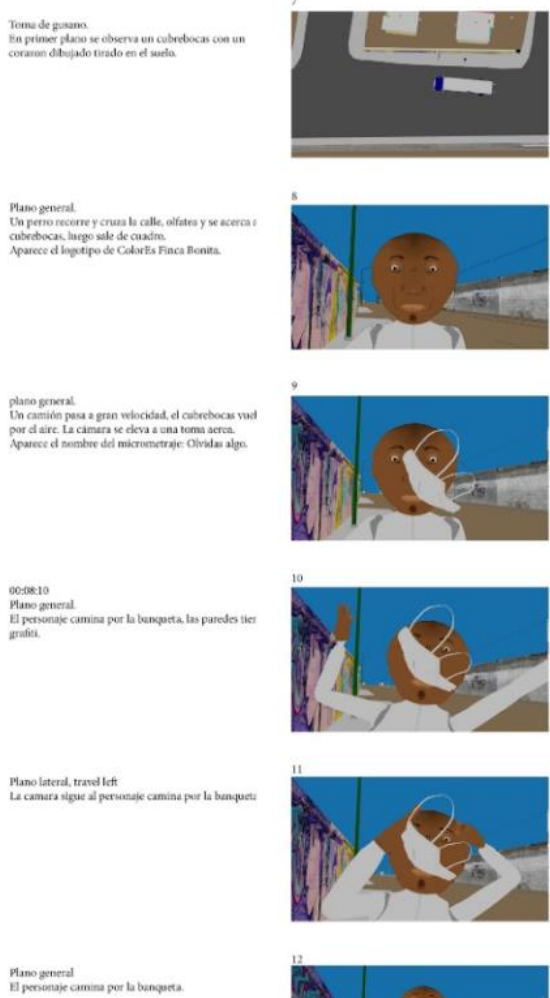
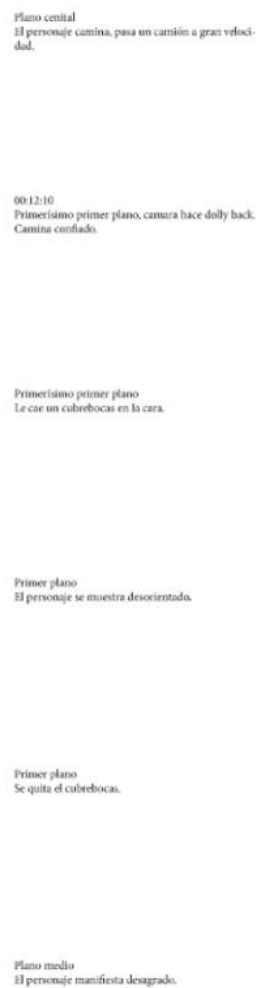

Figura 4. Páginas del storyboard. 2020. Fuente: elaboración propia.

De esta manera, la premisa se basa en una observación, la recurrencia de encontrar cubrebocas usados tirados en el suelo, principalmente en la calle representada en el micrometraje. El personaje tiene un desarrollo. Primero empieza como alguien que no se preocupa por el cuidado en el espacio público, pero el recuerdo de su hija le hace recapacitar y cambia su comportamiento.

La elección de tomar como personaje principal a un joven trabajador, visualizado en la figura 5, deriva de la consideración de que en los fraccionamientos, construidos durante los últimos 10 años en las periferias de Ciudad Juárez, habita un porcentaje considerable de usuarios que son matrimonios jóvenes en búsqueda de construir un patrimonio. Se decide representar a un personaje trabajador, ya que son quienes han tenido que asumir el riesgo del contagio con tal de poder lograr llevar el sustento a sus hogares. Esto también obedece a algunas de las respuestas que los usuarios dieron al contestar cuestionarios, las cuales se relacionaban a la idea de la esperanza de tener un patrimonio donde poder convivir con sus seres queridos. De modo que representar una situación cotidiana como salir de una casa e ir a laborar sintetiza al trabajo honrado, a pesar de vivir en una ciudad contextualizada por la violencia y la desigualdad social. 
JOSÉ FAUSTO • Desarrollo de micrometraje animado, una propuesta desde el diseño centrado en el usuario con enfoque social.

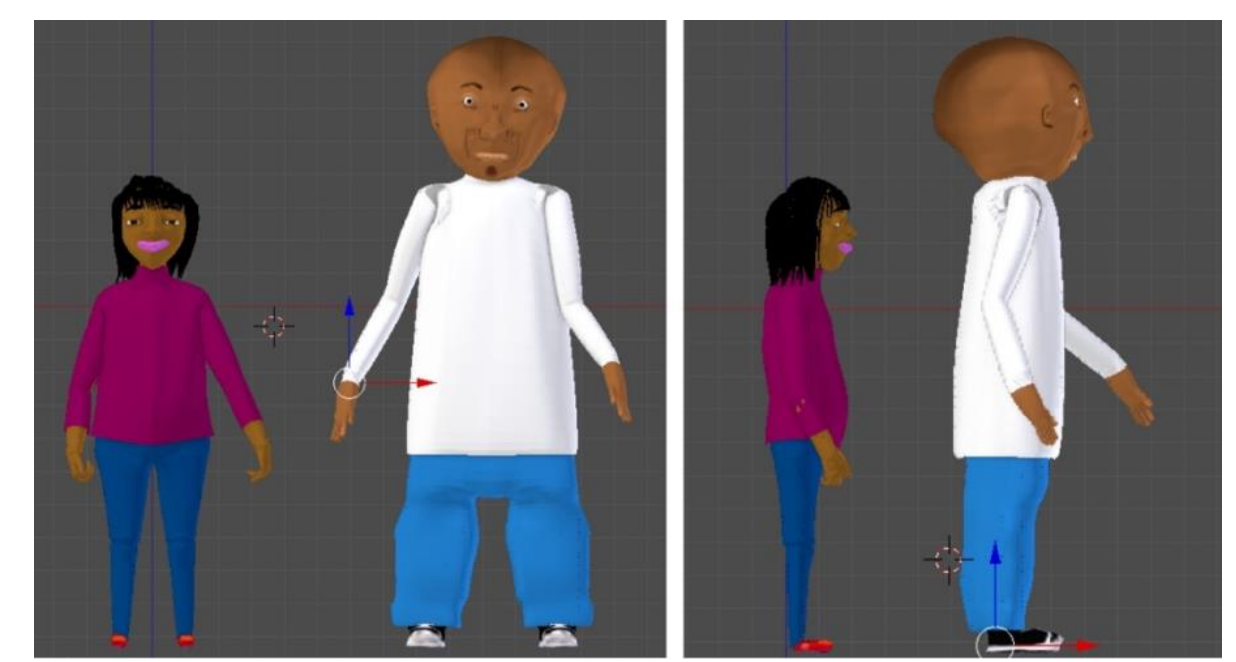

Figura 5. Proceso de diseño de personajes principales. 2020. Fuente: elaboración propia.

Existen elementos en la construcción del micrometraje que se encuentran abiertos a la interpretación de los usuarios. Otros aspectos, como el uso del cubrebocas, refieren al contexto de la pandemia vivida. Así mismo, hay un uso minimal de elementos en la representación. Las visualizaciones son respecto a dos personajes principales; un personaje secundario que es un chofer de camión de transporte público; un perro que olfatea cosas en la calle, camiones, la calle principal, casas y parte del inmobiliario urbano como postes de alumbrado. Sin embargo, consideramos que son suficientes para que los usuarios reconozcan que la proyección responde al fraccionamiento donde habitan, pero que además, también vincula e identifica a otras zonas de la ciudad, en relación al diseño urbano producido en Ciudad Juárez, al transporte público y al tipo de viviendas. La narración se encuentra abierta a la interpretación de situaciones por las que atraviesa el personaje principal, pero se denota que sale y regresa a su hogar después de una jornada de trabajo. En la figura 6 se presenta una fotografía de la calle Monte Blanco, principal escenario para nuestro micrometraje y una representación realizada en $3 \mathrm{~d}$ donde se incluyen algunos de los principales elementos que permitan a los usuarios reconocer ese espacio como propio. La principal característica, en cuanto a la resignificación, se encuentra en la gráfica urbana realizada dentro del proyecto ColorEs Finca Bonita, se trata de elementos de un imaginario asociado al paisaje urbano que favorecen una identificación. 

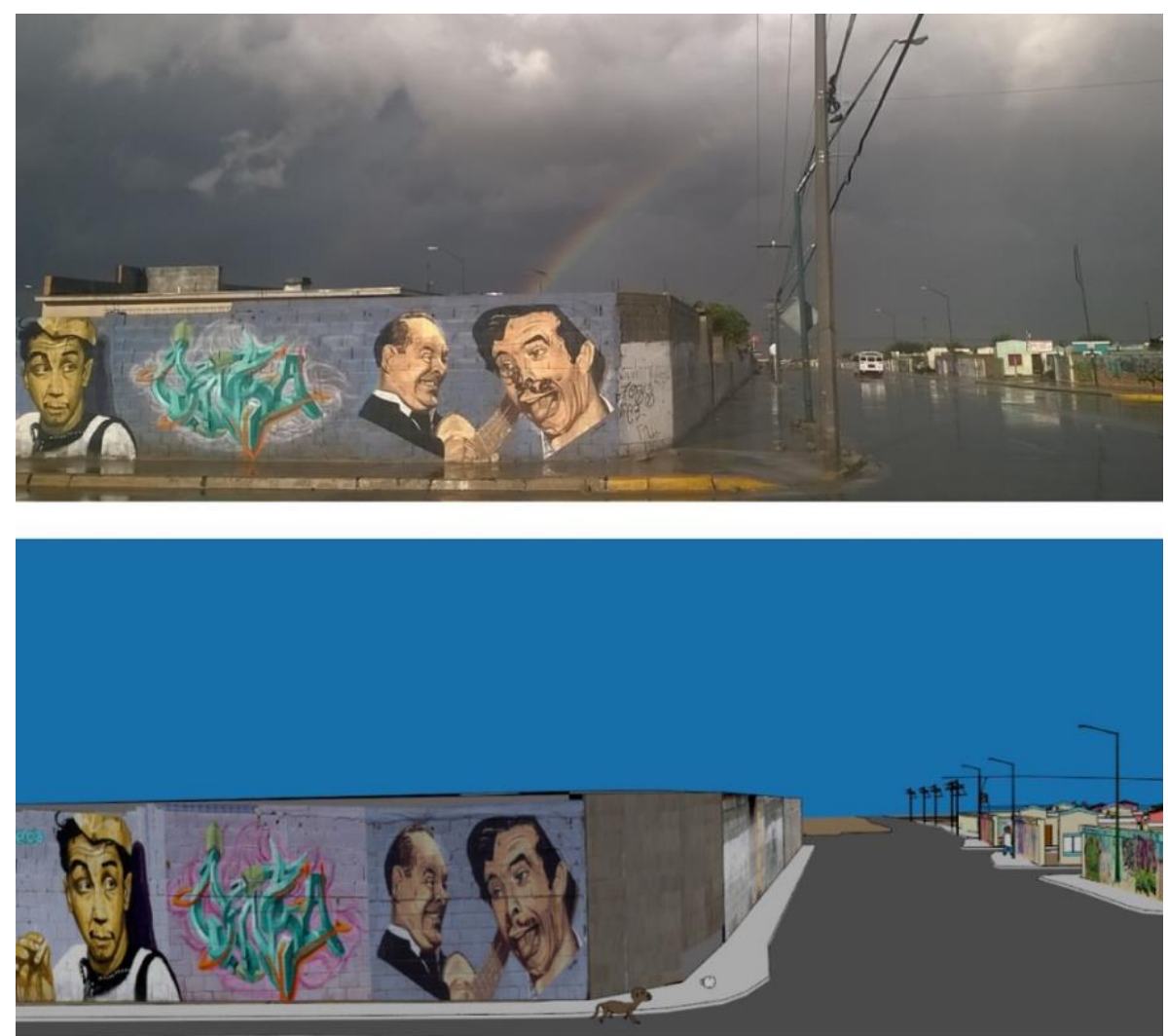

Figura 6. Fotografía de calle principal y representación en 3d. 2020. Fuente: elaboración propia.

Esta primera propuesta se realiza con un personaje masculino. Sin embargo, el proyecto contempla la realización de otra micronarrativa con la representación de un personaje principal femenino. La premisa es similar en cuanto a que refiere a la familia y los cuidados en el espacio público. La observación participante permite comprender que se generan muchas historias que pueden funcionar como inspiración para otros usuarios. Así mismo, es importante considerar cómo es vivido el espacio público por parte de los usuarios. En una crisis como la actual pandemia, existe mucha desinformación que deriva en el descuido de medidas de contención de propagación del virus. En este sentido, es preciso comprender la figura del usuario como transeúnte, es decir que los esquemas de comportamiento de este al pasar por un espacio transversal como una calle principal. Esto implica estar en el espacio público y tener una interacción con los otros habitantes dentro de un contexto inédito en el cual los patrones de conducta deben de adecuarse a una situación de crisis.

\section{Conclusiones}

La investigación responde a la pregunta de investigación que guía este artículo, pues, existe un cambio en la manera de vivir el espacio público, los procesos de identificación y de sentido de arraigo quedan relegados a planos secundarios a causa de las necesidades apremiantes durante una crisis como la pandemia del COVID-19. Resultados preliminares de la investigación permiten señalar que el espacio público urbano se puede analizar y deconstruir para atribuir significados nuevos, a través de la propuesta de micrometraje. A través de medios audiovisuales, es factible beneficiar en mecanismos de producción de imaginarios atribuidos a un lugar específico. El rol de observador participante proporciona una perspectiva desde la cual entender aspectos subjetivos en 
JOSÉ FAUSTO • Desarrollo de micrometraje animado, una propuesta desde el diseño centrado en el usuario con enfoque social.

la manera de vivir en el conjunto habitacional y en sus principales puntos de interacción económica y social. Herramientas como la cartografía conforman un ejercicio para representar el espacio. Sin embargo, se debe considerar que muchos aspectos no pueden ser incluidos debido a su complejidad. El registro en bitácora ayuda a apuntar cuestiones en torno a la percepción atribuida a ciertos espacios.Centrar la atención en el usuario para ofrecer un producto que no se vincula al consumo concede la oportunidad de fomentar atributos al imaginario de una manera orgánica. Es decir, favorecer en los procesos de identidad desde una perspectiva horizontal entre diseñadores y usuarios a través de ejercicios de participación.

La representación visual de prácticas espaciales y de determinados elementos que forman parte del imaginario colectivo atribuido a un lugar fomenta reflexiones respecto a la conformación de la identidad. En una situación de crisis se vuelve importante considerar estos aspectos. Ante un escenario inédito como el vivido en la pandemia, se generan nuevos hábitos y es preciso buscar la toma de conciencia en torno aquellas prácticas que generan contaminación. Sin embargo, la necesidad por trabajar o conseguir el sustento por medio de la venta de productos en la calle genera en algunos usuarios una especie de anomia ante el descuido o relajamiento de medidas para contener la propagación del coronavirus COVID-19.

Así mismo, es necesario entender que los usuarios asimilan de modos distintos las situaciones de crisis. Ante tal diversidad de entendimientos y de identidades, las limitaciones o posibilidades en un micrometraje necesariamente dejan significados abiertos a interpretaciones del usuario: son los huecos que se llenan de acuerdo a esquema. Sin embargo, las ideas principales y el mensaje de la premisa en una microhistoria se infieren por el desarrollo de una trama en un periodo de tiempo que puede ir de unos cuantos segundos a un par de minutos.

El aspecto de innovación en nuestra propuesta, para el habitante del conjunto de vivienda objeto de estudio, consiste en el ofrecimiento de un producto audiovisual sustentado en la cotidianidad. En otros términos, la búsqueda de otorgar elementos al sentido de arraigo se propone con un producto de diseño que no tiene antecedentes para habitantes de las zonas menos favorecidas de la ciudad. Después de todo, no hay propuestas audiovisuales de carácter artístico cultural que interpelen a los usuarios de las zonas periféricas de la ciudad, ya que cuando los medios de comunicación hacen referencia a la unidad habitacional, o a otras ubicadas en la misma zona, es para publicar noticias de hechos relacionados con la violencia.

Por último, las tecnologías permiten una democratización para la elaboración y difusión de productos culturales. Sin embargo, de igual manera que ocurre con otras prácticas alternativas de cultura, o al margen de las lógicas del mercado, el alcance suele ser limitado. En este sentido, los miembros de una comunidad o colectividad dispuestos a asumir el rol de generadores de contenido propio, por ejemplo en nuestro proyecto, requieren de un constante aprendizaje en la utilización de herramientas como el software libre para la producción de narrativas que hablen desde la perspectiva del usuario-habitante. 


\section{Referencias}

Casas, María (2002). “La identidad nacional en la sociedad de la información”. Revista Mexicana de Ciencias Políticas y Sociales 45 (2002): s.p. Web. Sep. 2020.

Delgado, Manuel. El animal público. Hacia una antropología de los espacios urbanos. Barcelona, España: Anagrama, 1999. Impreso.

Egri, Lajos. El arte de la escritura dramática. Fundamentos para la interpretación creativa de las motivaciones humanas (Trad. Peláez, S.). Ciudad de México, México: Universidad Nacional Autónoma de México, 2009. Impreso.

Escobedo, Elizabeth. La intertextualidad en la narrativa audiovisual de los micrometrajes animados: Imaginantes. Tesis de maestría. Colección de la Universidad Autónoma de Ciudad Juárez, 2015. Impreso.

Kumar, Vijay. 101 Design methods a structure approach for driving innovation in your organization. New Jersey, Estados Unidos: John Wiley \& Sons, 2013. Impreso.

Ledesma, María. "Cartografías del diseño social. Aproximaciones conceptuales". Anales del IAA. 2013. Web. Oct. 2020.

Lefebvre, Henri. La producción del espacio. (Trad. Martínez, E.). Madrid, España: Capitán Swing Libros, 2013. Impreso.

Malaver, Ary. "Microrrelato y nanofilología: dos enfoques nano(tecno)filológicos para entender las configuraciones de la escritura mínima(lizada)". Minificción y nanofilología: latitudes de la hiperbrevedad. Web. Madrid, España: Ed. Iberoamericana. 2017.

Mendoza, Jorge. "El transcurrir de la memoria colectiva: La identidad". Casa del Tiempo 5 (2009): s.p. Web. Oct. 2020.

Paisaje, Transversal. Escuchar y transformar la ciudad. Urbanismo colaborativo y participación ciudadana. Madrid, España: Catarata, 2019. Impreso.

Soja, Edward. Postmetrópolis. Estudios sobre las ciudades y las regiones. (Trads. Verónica Hendel y Mónica Cifuentes). Madrid, España: Traficantes de sueños, 2000. Impreso.

Vicherat, Daniela (2007). ¿Qué tienen en común la identidad, el espacio público y la democracia? En O. Segovia (Ed.), Espacios públicos y construcción social (pp. 57-68). Santiago, Chile: Ediciones Sur. Recuperado en junio 2019 de https://cadmus.eui.eu/handle/1814/8517

Olga Segovia (ed.), Espacios Publicos y Construccion Social. Hacia un ejercio de ciudadania, Santiago, Chile: Ediciones SUR, 2007. 